\title{
Tecnologias de tradução: implicações éticas para a prática tradutória
}

\section{Érika Nogueira de Andrade Stupiello*}

\begin{abstract}
This paper examines the ethical implications for the contemporary practice of translation with the use of translation memory systems. While considering ethics, it puts forward an analysis of the extension of the translational responsibility in the light of thoughts and proposals concerning an ethical attitude by the translator. This analysis is brought to the work scenario of the contemporary translator, who employs technological tools, integrates work groups with specific task assignments and is advised to carry out the work so as to recover previous translation options and turn in his/her terminological production together with the translation. We conclude that this work configuration ends up dissipating the translator's responsibility whereas it recovers the conception of translation as transposition of meaning between different languages.
\end{abstract}

Keywords: ethics; responsibility; translation; translation memories.

Resumo: Este trabalho compreende uma reflexão sobre as implicações éticas para a prática contemporânea de tradução com o uso de sistemas de memórias. Ao pensar em ética, propõe-se uma análise da extensão da responsabilidade tradutória à luz de pensamentos e propostas que versam o que constituiriam atitudes éticas por parte do tradutor. Essa análise é trazida para o cenário de atuação do tradutor contemporâneo, que faz uso de ferramentas tecnológicas, integra equipes de trabalho com designação específica de tarefas e é orientado a conduzir sua prática de forma a recuperar opções anteriores de tradução e a fornecer sua produção terminológica em conjunto com a tradução. Concluiu-se que essa configuração de trabalho acaba por dissipar a responsabilidade do tradutor ao mesmo tempo em que retoma a concepção de tradução como transposição de significados entre diferentes línguas.

Palavras-chave: ética; responsabilidade; tradução; memórias de tradução.

\footnotetext{
* Doutora em Estudos Linguísticos (Linguística Aplicada) pela Universidade Estadual Paulista (campus de São J osé do Rio Preto). Email: erika@traducao-interpretacao.com.br.
} 
Stupiello, E. N. A. - Tecnologias de tradução: implicações éticas para a prática tradutória

\section{Introdução}

O discurso de caráter ético em tradução tem se pautado, em diferentes épocas e pela perspectiva da tradição ocidental ${ }^{1}$, no estabelecimento de um conjunto ideal e universalmente aplicável de regras que delimitem o espaço de atuação do tradutor no trabalho de recuperação de sentidos determinados no texto de origem. Desde as remotas prescrições do humanista francês ETIENNE Dolet (1540), a tradução tem sido descrita como uma atividade que dependeria do estabelecimento de normas que, idealmente, dariam conta de determinar uma conduta específica para o trabalho do tradutor, fato que tem reflexos, até os dias de hoje, na forma como grande parte da sociedade concebe sua profissionalização.

Dos "princípios" estabelecidos por Pym (1997) para uma ética do tradutor, nas propostas mais recentes, como o "juramento" de CHESTERMAN (2001), ou mesmo códigos de ética profissionais locais, como o Código do Sindicato Nacional de Tradutores (Sintra) no Brasil, o que se busca é um comprometimento ético por esse profissional, que seja guiado por valores generalizantes que não compreendem as diversas situações vividas pelo tradutor contemporâneo.

Este trabalho apresenta uma reflexão sobre como algumas posturas associadas ao pensamento tradicional em relação à tradução afloram, ainda que implicitamente, nas expectativas de conduta do tradutor que, cada vez mais, faz uso de recursos tecnológicos com o intuito de conquistar ganhos em produtividade e se tornar mais competitivo.

\footnotetext{
${ }^{1}$ Segundo LefEVERE (1992: 6-7), o pensamento ocidental sobre tradução, da época da república romana até as primeiras publicações de cunho linguístico por Nida e Fedorov na década de 1930, seria caracterizado por uma forte inclinação normativa, restringindo o trabalho de tradução em termos de preceitos e categorizações do tipo "certo", "errado", "fiel" ou "livre".
} 
Stupiello, E. N. A. - Tecnologias de tradução: implicações éticas para a prática tradutória

Entre as diversas ferramentas atualmente disponibilizadas aos tradutores, os sistemas de memórias de tradução parecem ter encontrado melhor receptividade em meio aos profissionais que trabalham para a indústria de localização ou que prestam serviços em domínios especializados do conhecimento, como a tradução de manuais técnicos e outros textos que acompanham produtos comercializados em diferentes países.

Com base na análise das condições de trabalho do tradutor que emprega essas ferramentas, propôs-se um exame da extensão de sua responsabilidade ao integrar um processo maior de produção e distribuição de informações para públicos situados nos mais diversos locais do mundo, falantes de diferentes línguas e representantes de vasta diversidade cultural.

\section{A urgência da comunicação eletrônica multilíngue e as ferramentas de auxílio à tradução}

Em uma era que "tempo e espaço foram de tal modo comprimidos pelos satélites de telecomunicações e pelos meios eletrônicos, [...] que o tempo tornou-se sinônimo de velocidade e o espaço, sinônimo da passagem vertiginosa de imagens e sinais" (CHAUí 1992: 347), o papel mediador do tradutor na comunicação de materiais textuais circulados eletronicamente é encoberto na mesma medida em que aumenta a ênfase na imprescindibilidade da adoção e do domínio dos recursos das novas tecnologias de auxílio à tradução para atender às exigências de tempo e prazo do mercado global. As mudanças na forma como a comunicação se realiza, conforme descritas por Chauí, implicam em aumento na invisibilidade do tradutor, visto que a intervenção humana na tradução da comunicação entre diferentes línguas 
Stupiello, E. N. A. - Tecnologias de tradução: implicações éticas para a prática tradutória

parece ser incongruente em uma era considerada global. 0 esquecimento do caráter humano envolvido na tradução é uma das consequências da superioridade conferida às ferramentas tecnológicas, em especial, em sua capacidade de tornar o trabalho do tradutor mais rápido e preciso.

A ênfase está na urgência da comunicação multilíngue, sendo assim, empregar com eficiência ferramentas eletrônicas, como as memórias de tradução, torna-se uma exigência para o tradutor que presta serviços a segmentos como o da indústria de localização. 0 alcance do desempenho esperado para esse mercado acarreta necessariamente a observância de regras predefinidas para o trabalho com o texto, de forma que a conclusão de uma tradução promova o desenvolvimento de trabalhos futuros, em que trechos de textos traduzidos tornem-se úteis para aumentar o rendimento do tradutor, reduzindo, desse modo, custos e prazos. A aplicação dessas práticas de trabalho em tradução é favorecida pela constituição da comunicação textual no mundo contemporâneo, em que:

[...] em lugar da linguagem como rede de significantes e significados, signos e significações, haveria "jogos de linguagem" sem sujeito, e a comunicação seria feita por uma "nuvem de elementos narrativos", por séries de textos em intersecção com outros, produzindo novos textos nas instituições e fora delas (CHauí 1992: 347).

Os textos eletrônicos que circulam pela internet são, em sua maioria, disponibilizados em versões em duas ou mais línguas e desprovidos de qualquer referência autoral. A partir de um texto eletrônico é possível acessar outros textos por meio de links automáticos, que conduzem o usuário a realizar várias leituras, porém, muitas vezes sem qualquer indicação de início ou fim desses materiais. Essas características promovem a ilusão da possibilidade de produção e circulação de textos sem qualquer vínculo com seus autores e tradutores. 
Stupiello, E. N. A. - Tecnologias de tradução: implicações éticas para a prática tradutória

No caso específico da tradução, essa situação evidencia-se na própria divisão dos vastos projetos atualmente traduzidos em prazos sempre inversamente proporcionais à extensão e, por vezes, à complexidade dos textos. Para possibilitar a produção e a rápida circulação de informações em diferentes línguas, é comum a divisão dos trabalhos em equipes de tradutores que, situados em vários locais, recebem textos ou partes de textos extensos, muitas vezes parcialmente traduzidos e acompanhados por glossários para garantir a padronização dos trabalhos. Para textos de origem que precisam de referência autoral, é comum a expectativa de fidelidade, por parte do contratante, atrelar-se ao conteúdo dos dados terminológicos e fraseológicos cedidos com o propósito de guiarem as escolhas do tradutor. No contexto contemporâneo, a preocupação do contratante de uma tradução não se restringe à qualidade do produto final, mas também, à adequação dessa produção aos recursos oferecidos pelos sistemas de memórias para alcançar opções de tradução padronizadas e reaproveitáveis.

A consecução deste objetivo depende da aplicação de regras preestabelecidas de trabalho com o texto em conjunto com os sistemas de memórias. Essas regras visam manter o controle das opções e da elaboração da tradução pelo tradutor e em parte relembram algumas das prescrições outrora estabelecidas para regular a prática. A aplicabilidade de preceituações relacionadas ao pensamento tradicional sobre tradução e de proposições éticas para a prática contemporânea de tradução é problematizada a seguir. 


\section{A relatividade de proposições éticas frente à aparente invisibilidade tradutória contemporânea}

À primeira vista, a situação atual que se descreve para a prática de tradução de textos em meio eletrônico e para a indústria da localização parece não relembrar as posturas que contemplam, acima de tudo, 0 estabelecimento de normas para a condução e a avaliação do trabalho do tradutor. Se voltarmos ao passado, ainda que brevemente, veremos que muitas teorias que invocavam o critério de fidelidade incondicional em tradução fundamentavam-se no estabelecimento de "regras" para a atitude do tradutor diante de um consagrado autor estrangeiro e da superioridade do texto de origem. Um exemplo bastante conhecido nos estudos sobre tradução são as preceituações de Dolet (1540), considerado por BASSNETT (1980) um dos primeiros teóricos a formular uma teoria de tradução regida pela ética do dever. Em sua relação dos cinco princípios para uma boa tradução, Dolet simboliza o pensamento de sua época por defender, sobretudo, a imprescindibilidade de um entendimento perfeito do texto de origem pelo tradutor, uma vez que o sentido já estaria incrustado na fonte a espera de ser restituído em outra língua. Por esse prisma, a postura ética do tradutor adviria da subserviência a regras que projetavam sobremaneira a imagem da tradução como uma simples reprodução de um conteúdo predefinido.

A ordenação de Dolet e de muitos de seus sucessores como, por exemplo, TYtLer $(1791 / 1978)^{2}$ e seus "princípios" definidores de uma "boa tradução", sintetizam, segundo ARRoj o (1997), aquilo que o "senso comum" e

\footnotetext{
${ }^{2}$ A primeira proposta de Tytler foi publicada em 1791. A leitura para este trabalho baseou-se na edição de 1978, publicada pela J ohn Benjamins.
} 
Stupiello, E. N. A. - Tecnologias de tradução: implicações éticas para a prática tradutória

grande parte das teorias correlatas sobre tradução há anos têm defendido como "princípios éticos" para o tradutor, fundamentados na crença da

[...] possibilidade de elaborar uma ética geral que pudesse ser implementada universalmente, abrangendo todas as atividades de tradução, independentemente das línguas, e dos interesses ideológicos, culturais, políticos e históricos e das circunstâncias envolvidas (ARROJ o 1997: 6) . $^{3}$.

À luz das reflexões de cunho pós-estruturalista, propostas de estabelecimento de uma ordenação ética totalizadora e aplicável à diversidade de situações de trabalho do tradutor são questionadas e desaprovadas por "revelarem um código de ética que está indiscutivelmente associado aos interesses e aos valores que os produzem e os tornam possíveis" (ARRojo 1997: 16). Cada norma ou prescrição, ainda que suavizadas como "orientações" de um manual de usuário, refletem a imagem da tradução em um determinado tempo e lugar, assim como a expectativa de que a obediência a esses preceitos garantiria a qualidade do trabalho final.

Para PyM (1997), o estabelecimento de normas de conduta do tradutor seria uma tentativa de impor responsabilidade sobre o trabalho que realiza, além de uma forma de promover a consecução da tradução pela submissão a regras idealizadas. Conforme explica,

[...] governar as relações de modo prescritivo significa, acima de tudo, determinar o que os outros têm o direito de exigir do tradutor: fidelidade, exatidão, rapidez, preços razoáveis, solidariedade em relação aos outros tradutores, respeito ao segredo profissional. Esses princípios relacionais constituem um tipo de pensamento ético. Eles estabelecem o que o tradutor deve ou não fazer (PYM 1997: 68).

Idealmente, um tradutor capaz de se adequar e seguir as regras de conduta a ele determinadas seria, na visão de quem as prega, "um tradutor

\footnotetext{
${ }^{3}$ Esta e as demais traduções de citações em língua estrangeira foram feitas pela autora do trabalho.
} 
Stupiello, E. N. A. - Tecnologias de tradução: implicações éticas para a prática tradutória

altamente profissional, um produto puro dos códigos da profissão" (PYM, 1997: 68). Seria também pela imposição de normas de conduta profissional que 0 contratante de uma tradução teria a possibilidade de controlar o processo de forma a atingir o produto por ele almejado. Como afirma CHESTERMAN (2001), 0 estabelecimento de normas seria uma forma de buscar o atendimento de expectativas determinadas, sendo tais normas

[...] geralmente aceitas (em uma cultura específica) na medida em que parecem servir a valores prevalecentes, inclusive valores éticos como verdade e confiança. Comportar-se de maneira ética, desse modo, significa comportar-se da maneira esperada, de acordo com as normas, não surpreendendo o leitor ou o cliente (CHESTERMAN 2001: 141).

De acordo com Pym (1997) e Chesterman (2001), a postura ética do tradutor adviria de sua adoção da conduta desejada por quem a prescreve. Preceituar o fazer tradutório seria uma forma de fixar uma determinada maneira do tradutor trabalhar, conforme a imagem idealizada especialmente sobre o produto desse trabalho, a tradução. Essa imagem é descrita por Pym ao relacionar a produção tradutória a um "processo de fabricação", do qual se espera resultar um produto acabado, um "text achevé", pois, como questiona o próprio autor:

[...] para traduzir plenamente, isto é, para ocupar o espaço próprio do tradutor, deve-se produzir traduções, objetos acabados, concluídos. Afinal, sem objeto, sem tradução material, sem realização, sem trabalho cumprido, pelo que o tradutor será responsável? (PYM 1997: 74).

A expectativa do contratante de uma tradução é a de que o texto a ser traduzido expressará todo o conteúdo do texto de origem e é essa a responsabilidade que se impõe ao tradutor. Para Pym, no momento em que 0 tradutor aceita realizar um trabalho, ele já se torna responsável pelo produto 
Stupiello, E. N. A. - Tecnologias de tradução: implicações éticas para a prática tradutória

final. Esse é o primeiro princípio para uma ética do tradutor proposto por esse teórico a partir do questionamento "Faut-il traduire?" [Deve-se traduzir?]. Sua decisão de realizar uma tradução ou deixar de fazê-la estabelece, como segundo princípio, a medida da responsabilidade tradutória, ou seja, o tradutor é responsável na medida em que aceita e se dispõe a traduzir. Como defende PYM (1997: 136), “o tradutor não é diretamente responsável pela matéria a ser traduzida, pelas normas da tradução", mas profissionalmente por sua decisão de aceitar ou não uma tradução.

Como terceiro princípio, o autor determina que os "processos tradutórios não devem ser reduzidos à oposição entre duas culturas" e que a ética do tradutor "deve ser rigorosamente intercultural" (РYM 1997: 136). Observa-se neste preceito uma postura que idealiza a neutralidade das relações que se constroem entre duas línguas pela tradução, assim como a possibilidade do tradutor realizar seu papel de mediador, mantendo-se imparcial em seu trabalho com diferentes línguas e culturas.

Por quarto princípio, PYM (1997: 136-7) defende que "os gastos de recursos suscitados pela tradução não devem ultrapassar o valor dos benefícios da relação intercultural correspondente", sendo o esforço investido na tradução tão importante quanto seu resultado. No quinto e último princípio, o teórico assevera ser responsabilidade do tradutor "contribuir para estabelecer a cooperação intercultural estável e em longo prazo".

Enumerada em cinco máximas, a ética do tradutor de Pym busca favorecer a cooperação entre o tradutor e seu cliente. Acima de tudo, 0 "tradutor ético" por ele vislumbrado seria aquele que avalia a finalidade da tradução para decidir o que e como traduzir, de forma a maximizar a colaboração com o cliente e "a concentrar os esforços de tradução onde os mal-entendidos impedem a cooperação" (PYM 1997: 123).

Atribuir ao tradutor a responsabilidade pelo produto de seu trabalho, ainda que este seja caracterizado como um ato de cooperação para a realização da comunicação, pode parecer ser uma forma de legitimar a 
Stupiello, E. N. A. - Tecnologias de tradução: implicações éticas para a prática tradutória

profissão, pela escolha feita pelo tradutor de traduzir ou não um texto ou parte dele. Pym parece instaurar um paradoxo entre o tradutor soberano que vislumbra, responsável por suas escolhas (até mesmo pela opção de não traduzir), e aquele que se subordina as relações de diversas ordens como "as coisas, as orientações do cliente, as normas em vigor que se aplicam à tradução, suas próprias condições de trabalho" (Pym 1997: 97). Entretanto, esses condicionantes não são levados em consideração em seus princípios éticos, que se atêm a atrelar a responsabilidade tradutória à promoção da comunicação entre línguas e culturas, deixando de considerar os limites dessa responsabilidade em relação à diversidade de condições impostas ao tradutor em seu trabalho. Na visão de GodARD (2001: 57), a proposta de Pym seria de cunho instrumentalista e falharia por sua abordagem generalizante, na medida em que "persegue uma ética para todas as modalidades de tradução, independentemente de seus conteúdos".

A prática de tradução como um ato de cooperação com o intuito de promover o entendimento fundamenta também a reflexão de CHESTERMAN (2001: 141), que atribui ao tradutor a tarefa principal de perseguir a compreensão entre as culturas, pelo "entendimento de textos, mensagens, sinais, intenções, significados etc.". Cuidadoso em relativizar a noção de "entendimento" que prega, Chesterman defende que "entender uma tradução significa chegar a uma interpretação compatível com a intenção comunicativa do autor e do tradutor (e em alguns casos também do cliente) a um grau suficiente para um determinado fim" (2001: 141).

A postura ética do tradutor de Chesterman seria regida por uma proposta de um "juramento hieronímico", em referência a São Jerônimo. Formulada com base no juramento hipocrático, a lista com os princípios elencados por esse teórico é valorizada como uma forma de "fortalecer 0 credenciamento internacional de tradutores". O comprometimento do tradutor com o próprio juramento encabeça a lista, que abrange valores como verdade, clareza, lealdade e confiabilidade: 
Stupiello, E. N. A. - Tecnologias de tradução: implicações éticas para a prática tradutória

1. J uro preservar este J uramento com o melhor de minha capacidade e de meu julgamento. [Compromisso]

2. Juro ser um membro fiel da profissão dos tradutores, respeitando sua história. Estou disposto a compartilhar meus conhecimentos com os colegas e transmiti-los a tradutores em treinamento. Não trabalharei por honorários ilegítimos. Sempre traduzirei com o melhor de minha capacidade. [Lealdade à profissão]

3. Usarei meus conhecimentos para maximizar a comunicação e minimizar desentendimentos entre barreiras linguísticas. [Entendimento]

4. Juro que minhas traduções não representarão seus textos de origem de maneiras inj ustas. [Verdade]

5. Respeitarei meus leitores tentando tornar minhas traduções o mais acessíveis possível, de acordo com as condições de cada trabalho de tradução. [Clareza]

6. Comprometo-me em respeitar os segredos profissionais de meus clientes e não tirar proveito dessas informações. Prometo respeitar prazos e seguir as instruções dos clientes. [Confiabilidade]

7. Serei honesto sobre minhas próprias qualificações e limitações. Não aceitarei trabalho que não seja de minha competência. [Honestidade]

8. Informarei meus clientes sobre problemas não resolvidos, e estou de acordo em resolver casos de controvérsia por meio de arbitragem. [J ustiça]

9. Farei tudo o que puder para manter e aprimorar minha competência, inclusive todo o conhecimento e as habilidades linguísticas, técnicas e outros. [Empenho pela excelência] (CHESTERMAN 2001: 153).

A ética defendida por Chesterman fundamenta-se no compromisso assumido pelo tradutor em "fazer a coisa certa", ao empenhar-se ou, pelo menos, prometer se empenhar, em por em prática uma série de atitudes, que vão desde a lealdade à profissão, ao contínuo esforço pelo aprimoramento profissional, e culminam na concepção de um profissional digno de confiança. Subjacente aos valores listados estaria a capacidade de entendimento, uma vez que, o tradutor digno de confiança teria condições de entender a mensagem do texto que traduz, afinal, como defende o teórico, "para 0 tradutor, essa é naturalmente uma tarefa primária: entender o que o cliente quer, entender o texto de origem, entender o que se espera que os leitores entendam" (CHESTERMAN 2001: 152). 
Stupiello, E. N. A. - Tecnologias de tradução: implicações éticas para a prática tradutória

Em relação às prescrições de DoLet (1540) e TYTLER (1978), é notória em CHesterman (2001) a mudança de abordagem no que diz respeito à intenção de prever e controlar o trabalho do tradutor. Os primeiros teóricos citados apoiaram-se em regras e normas específicas, com o intuito de reger e limitar a interferência do tradutor no texto de origem. Suas ordenações visavam impelir o tradutor a se prender à reprodução do conteúdo de origem e se manter subserviente ao texto e ao autor. A concepção de ética por eles sustentada estava diretamente relacionada à noção de fidelidade à origem.

Nas máximas apresentadas por PYM (1997) e no juramento de CHESTERMAn (2001) temos por característica comum a generalidade na expressão das proposições dos autores. Ambos os teóricos atrelam suas propostas à pressuposição de responsabilidade do tradutor por seu trabalho. Nas palavras de Pym (1997: 67), "se o tradutor não fosse responsável, se não tivesse de aceitar a responsabilidade por nenhuma de suas escolhas, não teria nenhum problema de ordem ética". A adoção de um discurso abrangente constitui um aspecto bastante comum em princípios qualificados como éticos, especialmente pelo fato de terem por objetivo primário guiar e orientar a conduta de uma determinada prática, sejam eles usados em um discurso normativo, como o postulado por Dolet, ou expostos em forma de axiomas ou juramento, como propõem PYM e CHESTERMAN, respectivamente.

O tratamento da ética por Chesterman, por exemplo, que substitui o ato de "dever" pelo de "prometer", abrange as relações com o contratante de uma tradução, entre tradutores e do tradutor consigo, em seu empenho pelo constante aprimoramento. Seu foco é o tradutor inserido em sua prática e não mais a aspiração pela neutralidade de sua prática. Ainda assim, vemos que, apesar de almejar a generalização de qualidades universalmente desejadas e consideradas nobres em qualquer profissional, valores (expressos entre colchetes) como compromisso, lealdade, verdade, clareza, honestidade e confiabilidade parecem se dispersar pela própria forma como o trabalho do tradutor é concebido e contratado e nas situações em que esse profissional 
Stupiello, E. N. A. - Tecnologias de tradução: implicações éticas para a prática tradutória

desempenha seu trabalho para mercados como o da localização, que lidam com textos volumosos e em formato eletrônico.

Essa é também uma questão problemática para o único código de ética que determina os princípios para a conduta de trabalho do tradutor profissional no Brasil. A responsabilidade profissional, prevista no Capítulo V, e o respeito ao trabalho confiado, o texto de origem, constituem máximas do Código de Ética do Tradutor adotado pelo Sindicato Nacional de Tradutores do Brasil (Sintra), conforme determinam os princípios do referido código elencados a seguir:

\section{CAPÍTULO I}

Princípios Fundamentais

Art. 10 - São deveres fundamentais do tradutor:

$\$ 1$ o respeitar os textos ou outros materiais cuja tradução lhe seja confiada, não utilizando seus conhecimentos para desfigurá-los ou alterá-los;

$\S 20$ exercer sua atividade com consciência e dignidade, de modo a elevar o conceito de sua categoria profissional;

$\$ 30$ utilizar todos os conhecimentos linguísticos, técnicos, científicos, ou outros a seu alcance, para o melhor desempenho de sua função; $\S 4^{\circ}$ empenhar-se em participar da tomada de decisões do seu órgão de classe e em vê-las acatadas, em particular no que se refere à remuneração justa, às condições de trabalho e ao respeito aos direitos do tradutor;

$\S 50$ solidarizar-se com as iniciativas em favor dos interesses de sua categoria, ainda que não Ihe tragam benefício direto.

\section{CAPÍTULO II}

Relações com os Colegas

Art. $2^{\circ}$ - 0 tradutor deve tratar os colegas com lealdade, respeito e solidariedade.

Art. 30 - 0 tradutor deve abster-se de qualquer ato que signifique concorrência desleal a outros tradutores ou exploração do trabalho de colegas, seja em sentido comercial ou outro.

\section{CAPÍTULO III}

Relações com o Contratante do Serviço

Art. 40 - 0 tradutor deve servir lealmente ao interesse de quem lhe contratou o serviço. 
Stupiello, E. N. A. - Tecnologias de tradução: implicações éticas para a prática tradutória

Art. 5o - O tradutor deve empenhar-se em lavrar previamente por escrito, com o contratante do serviço, as obrigações recíprocas concernentes ao trabalho em causa.

\section{CAPÍTULO IV}

Do Segredo Profissional

Art. 60 - O tradutor é obrigado a guardar segredo sobre fatos de que tenha conhecimento por tê-los visto, ouvido ou deduzido no exercício de sua atividade profissional, a menos que impliquem delito previsto em lei ou que possam gerar graves consequências ilícitas para terceiros.

\section{CAPÍTULO V}

Responsabilidade Profissional

Art. 70 - O tradutor é responsável civil e penalmente por atos profissionais lesivos ao interesse do contratante de seus serviços, cometidos por imperícia, imprudência, negligência ou infrações éticas.

\section{CAPÍTULO VI}

Aplicação deste Código

Art. 8 - Cabe ao Sindicato Nacional de Tradutores - SINTRA a apuração de faltas cometidas contra este Código de Ética, a aplicação das penalidades previstas nos Estatutos do SINTRA e, quando cabível, o encaminhamento do caso aos órgãos competentes.

Art. 9o - Com discrição e fundamento, o tradutor dará conhecimento ao SINTRA dos fatos que constituam infração às normas deste Código. (SINTRA, Sindicato Nacional dos Tradutores, Estatutos, Código de Ética do Tradutor, 13 dez. 2004. $)^{4}$

É notório como o Código de Ética do Tradutor do Sintra confere visibilidade ao tradutor, como agente que responde diretamente por seu trabalho e nas relações estabelecidas com clientes e outros tradutores. 0 referido código, em seu Capítulo V, até mesmo estabelece que o tradutor é "responsável civil e penalmente" por suas ações no exercício de sua profissão, o que imprime comprometimento com o serviço que lhe é confiado pelo cliente. Por outro lado, se aplicarmos as disposições específicas desse capítulo à atuação do tradutor brasileiro no segmento de localização, que se caracteriza pela compartimentação do trabalho entre diferentes prestadores de serviço, percebe-se como se torna complexo vincular o tradutor a esses

\footnotetext{
${ }^{4}$ Conforme informado pela ex-presidente do Sintra, Profa. Dra. Heloisa Gonçalves Barbosa, entre 2003 e 2005, esse código foi retirado da página eletrônica do Sindicato, embora continue fazendo parte dos estatutos dessa associação profissional.
} 
Stupiello, E. N. A. - Tecnologias de tradução: implicações éticas para a prática tradutória

princípios e, em particular, atribuir-Ihe a responsabilidade pelo trabalho final assim produzido.

As condições de produção de trabalhos de tradução em meio eletrônico, especialmente para a indústria da localização, favorecem 0 deslocamento da responsabilidade tradutória pelo trabalho final. A obtenção do desempenho esperado atrela-se necessariamente à observância de regras predefinidas para o trabalho com o texto, de forma que a conclusão de uma tradução promova o desenvolvimento de trabalhos futuros, em que trechos de textos traduzidos tornem-se úteis para aumentar o rendimento do tradutor, reduzindo, desse modo, custos e prazos. Nesse contexto, é problemática a visão de tradução de Pym como "um produto acabado", considerando-se a fragmentação do texto de origem para tradução em equipe e as diversas etapas pelas quais passa 0 texto até sua conclusão. 0 tradutor autônomo que presta serviços para essa indústria é, pelo menos aos olhos de quem 0 contrata, apenas um membro de uma equipe coordenada por gerentes de projetos e que inclui também engenheiros de software, revisores e profissionais de editoração. Nesse espaço de produção de traduções, grande parte das estratégias colocadas em prática, envolvendo a adoção de uma terminologia específica, seu reaproveitamento com o auxílio dos sistemas de memória e seu controle com o uso de banco de dados, não constituem decisões do tradutor, devendo ser por ele acatadas e cumpridas. Esse fato favorece o descomprometimento do tradutor que, por não conhecer ou ser mantido afastado do processo de preparação do material traduzido como um todo, não se vincula à sua conclusão. Como consequência, o tradutor torna-se e faz-se, ainda que aparentemente, invisível aos olhos do contratante e do usuário final da tradução. 
Stupiello, E. N. A. - Tecnologias de tradução: implicações éticas para a prática tradutória

\section{Considerações finais}

Quando grande parte dos textos de origem encontra-se em meio digital, se dispersa a responsabilidade do tradutor, que passa a lidar com um original em constante processo de atualização e, em geral, fragmentado para possibilitar a tradução e o tratamento em equipe. Sendo o comprometimento do tradutor com o trabalho que realiza limitado também pelas ferramentas que 0 auxiliam, desfazem-se as relações que o tradutor constrói com o texto que produz, um fato que repercute diretamente na concepção ética da prática.

Como discutido neste trabalho, no momento em que a atuação do tradutor é ocultada ou relegada a um segundo plano em relação ao desempenho de ferramentas como aos sistemas de memórias, sua relação com o texto que traduz limita-se ao pequeno espaço que lhe é permitido intervir no texto. Nesse sentido, o trabalho humano de recriação de sentidos é encoberto na produção tradutória, especialmente pela determinação de reutilização de opções anteriores de tradução recuperadas pelos sistemas de memórias e pelo confinamento do trabalho do tradutor aos segmentos predefinidos de texto. Essa restrição da atuação do tradutor limita também a medida de sua responsabilidade, já que não seria cabível ele responder por um trabalho do qual só traduziu trechos e que desconhece na íntegra.

Seus conhecimentos linguísticos e a especialidade em uma determinada área do conhecimento podem ser colocados em segundo plano se entrarem em conflito com determinada opção anterior de tradução armazenada na memória a espera de se fazer valer em uma nova tradução. A expectativa e a prescrição de aproveitamento máximo do que é oferecido pela memória de tradução confere primazia às relações textuais formadas por esse sistema, em especial ao se considerar que: 
Stupiello, E. N. A. - Tecnologias de tradução: implicações éticas para a prática tradutória

[...] nossas tecnologias agora realizam o trabalho de memória para nós. A linguagem do passado é, assim, retirada de seus contextos subjetivos; é armazenada; torna-se anônima e desumanizada. Nossas relações com o outro, através de culturas no tempo e no espaço são lembradas para nós, e, dessa maneira, não se tornam parte de nós (PYM 2004: 126).

Não sendo "parte" do tradutor e, assim, deixando de lhe oferecer a possibilidade de construir uma relação com outra língua e cultura, o texto que Ihe cabe traduzir é reduzido aos fragmentos contextuais recuperados da memória de tradução. Segmentos de traduções reaproveitados e introduzidos no novo contexto do trabalho em desenvolvimento tendem a encobrir a intervenção tradutória, inclusive pelo não reconhecimento, por parte do contratante do trabalho, da revisão e da adequação feitas pelo tradutor para que esses segmentos tornem-se coerentes com o texto traduzido de que farão parte.

Ciente do papel que desempenha na produção de textos para circulação em meio eletrônico e do pouco controle que exerce sobre a produção final dos textos que é contratado a traduzir, o tradutor também encontra conveniência no encobrimento de sua intervenção, até mesmo, aceitando que seu nome não conste no trabalho realizado. Frequentemente parte de uma equipe, 0 trabalho do tradutor e sua intervenção difundem-se entre as traduções realizadas por outros tradutores para, então, fundirem-se em um só texto, uma "colcha de retalhos" cujas emendas seriam garantidas pelo controle terminológico promovido com o auxílio dos bancos de dados formados pelos sistemas de memórias.

As condições de trabalho do tradutor contemporâneo que faz uso de sistemas de memórias de tradução convidam a retomarmos as concepções sobre ética de teóricos como Pym (1997) e CHESTERMAN (2001). Se pensarmos como Pym que: 
Stupiello, E. N. A. - Tecnologias de tradução: implicações éticas para a prática tradutória

[...] uma tradução só existe plenamente graças à crença, por parte do receptor, que tal texto, denominado tradução, foi produzido segundo um processo, que se chama traduzir, e que o outro, denominado texto fonte ou original, é o ponto de partida desse processo, mas não provém, ele mesmo, do traduzir. Dito de outra maneira, o receptor crê que a tradução representa plenamente o original. Frequentemente falsa, ideologicamente muito manipulável, talvez seja por essa crença - ilusão, até mesmo mentira - que o tradutor é, em última instância, responsável (PYM 1997: 76).

Talvez, possamos inferir que os valores contidos na proposta de juramento ético do tradutor como "lealdade à profissão", "entendimento", "verdade", "clareza", "confiabilidade" e "honestidade" baseiam-se em crenças sobre o que constituiria o comportamento ideal em determinadas condições de trabalho. Nas situações descritas neste trabalho, esses valores ganham nova dimensão pelo modo como o tradutor executa seu trabalho ao fazer uso dos recursos tecnológicos a ele disponibilizados, ou até impostos, para manter-se atuante diante das exigências de mercados como o de localização.

Se retomarmos o juramento proposto por Chesterman no contexto de atuação do tradutor que faz uso de ferramentas tecnológicas de auxílio à tradução, pode-se repensar como se constrói a relação de "lealdade à profissão", defendida por esse autor, na atualidade. Ser leal pode significar compartilhar memórias para colaborar com colegas autônomos que se sentem em desvantagem em relação aos extensos bancos de dados terminológicos com que muitas agências contam, pelo fato de exigirem dos tradutores que Ihes prestam serviços que forneçam a memória formada com a tradução contratada. Por esse prisma, a lealdade à profissão pode ser contrária à virtude de confiabilidade por parte do tradutor, também pregada por Chesterman, especialmente em se tratando do respeito ao segredo profissional do cliente. Compartilhar bancos de dados formados a partir de traduções contratadas pode constituir uma forma de "tirar proveito dessas informações", um ato contrário àquele defendido por CHESTERMAN (2001: 153). 
Stupiello, E. N. A. - Tecnologias de tradução: implicações éticas para a prática tradutória

A busca por "entendimento" para "maximizar a comunicação e minimizar desentendimentos", sobre a qual se assenta a proposta de Chesterman, pode estar sendo influenciada pelo modo como as memórias são projetadas e empregadas pelo tradutor. 0 próprio projeto desses sistemas, com ambientes de trabalho que limitam o olhar do tradutor a caixas com textos segmentados para tradução ou, ainda, colunas com texto de origem e tradução compartimentados e alinhados, induz o tradutor a se apegar às opções oferecidas pela memória, atendo-se às orientações fornecidas para reaproveitamento máximo de trabalhos anteriores na execução de uma nova tradução. Do modo como é executado com o apoio dos sistemas de memórias, o trabalho de tradução é controlado a fim de produzir textos traduzidos idealmente padronizados e, de preferência, que ocultem a intervenção da interpretação do tradutor. Língua e cultura perdem o vínculo nesse esforço para padronização de traduções com o uso das memórias, à medida que a expressividade particular de cada língua é deixada de lado na perseguição por pares bilíngues simétricos na operação de recuperação promovida pelos sistemas de memória. 0 empenho pela "clareza" e por respeito aos leitores já não dependeria mais exclusivamente das escolhas do tradutor na elaboração do texto traduzido, mas principalmente das circunstâncias em que ele exerce seu trabalho. Essa situação, levada às últimas consequências, pode por em xeque o esforço em prol do "entendimento entre culturas" defendido por Chesterman (2001).

Nesse sentido, pode-se concluir com KoSKINEN (2000: 108) que "a ética da tradução não pode ser totalmente coberta pelo regulamento das relações entre os textos de origem e meta, e nem entre os participantes imediatos no processo de tradução". O modo como são contratados e desenvolvidos projetos de tradução contemporâneos assistidos por ferramentas eletrônicas, como os sistemas de memória, têm promovido mudanças definitivas na maneira como o tradutor atua e em como seu trabalho é reconhecido e remunerado. 
Stupiello, E. N. A. - Tecnologias de tradução: implicações éticas para a prática tradutória

Concluiu-se que a tradução está experimentando um retorno à tão combatida concepção de transposição de significados entre línguas, feita por um tradutor com condições de se manter neutro. Essa aparente neutralidade seria garantida pela divisão e dispersão do trabalho entre vários tradutores. As diversas redes de relações linguísticas e culturais outrora, e ainda em outros setores de trabalho, construídas pelo tradutor na tradução já não são mais suas, mas misturam-se e difundem-se entre os diversos agentes de um trabalho incessantemente segmentado e pelo qual já não se pode mais atribuir um responsável.

\section{Agradecimento}

Agradeço à Fapesp pelos recursos da bolsa de doutorado (processo no. 06/60974-5) que possibilitaram a pesquisa para elaboração deste artigo.

\section{Referências bibliográficas}

ARroj 0, R.. Asymmetrical relations of power and the ethics of translation. TextconText, 1997 v. 11, pp. 5-24.

. The revision of the traditional gap between theory $\&$ practice $\&$ the empowerment of translation in postmodern times. The translator, $v$. 4, n. 1, p. 25-48, 1998.

AUSTERMÜHL, F. Electronic tools for translators. Manchester: St. J erome., 2001.

BASSNETT, S. Translation studies. London: Methuen, 1980.

Chauí, M.S. O público, o privado, despotismo. In: Novaes, A. (Org.). Ética. São Paulo: Companhia das Letras, 1992, p. 345-390.

Chesterman, A. Proposal for a Hieronymic Oath. In: Pym, Anthony (Ed.). The Translator: the return to ethics. Manchester: St. Jerome. v. 7, n. 2, p. 139-154. 
Stupiello, E. N. A. - Tecnologias de tradução: implicações éticas para a prática tradutória

DOLET, É. La manière de traduire bien d'une langue en autre. Lyon: E. Dolet, 1540.

GODARD, B. L'éthique du traduire: Antoine Berman et le "virage ethique" en traduction. TTR: Traduction, Terminologie, Rédaction. Montréal: Canadá, v. 14, n. 2, p. 49-82, 2001.

KOSKINEN, K. Beyond ambivalence: postmodernity and the ethics of translation. (Acta Universitatis Tamperensis 774). Tampere: University of Tampere, 2000.

LefeVere, A. Translating literature. New York: Modern Language Association of America, 1992.

Pym, A. Pour une éthique du traducteur. Arras: Artois Presses Université, 1997.

- Translational ethics and electronic technologies. A profissionalização do tradutor. Lisboa: Fundação para a Ciência e a Tecnologia/União Latina, 2004, p. 121-126.

SINTRA, Sindicato Nacional dos Tradutores, Estatutos, Código de Ética do Tradutor, 13 de dezembro de 2004.

TYtLeR, A.F. Essay on the principles of translation. Amsterdam: John Benjamins, 1978. 